\title{
Aseptic HLA B27-positive spondylodiscitis: decreased 18F-FDG uptake after etanercept treatment
}

\author{
M. Benucci ${ }^{1}$, A. Damiani', A. Arena' ${ }^{2}$, M. Infantino ${ }^{3}$, M. Manfredi ${ }^{3}$, F. Li Gobbi ${ }^{1}$ \\ ${ }^{1}$ Rheumatology Unit, S. Giovanni di Dio Hospital, Firenze; \\ ${ }^{2}$ Nuclear Medicine Unit, New Hospital, Prato; \\ 3Immunology and Allergology Laboratory Unit, S. Giovanni di Dio Hospital, Firenze, Italy
}

\section{SUMMARY}

We observed a 69-year old man suffering from HLA B27 ankylosing spondylitis with persistent night back pain. 18F-FDG-PET/CT showed an increased metabolism at the level of the spinal space of L2-L3, L3-L4 with increased uptake compatible with spondylodiscitis. He started therapy with etanercept 50 $\mathrm{mg} /$ week. After six months of treatment repeated testing showed no uptake of the discs and vertebral bodies.

Key words: Spondylodiscitis; etanercept; ankylosing spondylitis.

$\mathrm{W}^{\mathrm{c}}$ observed a 69-year-old retired male, whose father suffered from HLA B27-positive ankylosing spondylitis, with persistent night back pain and alternating episodes of sciatica. He improved on etoricoxib $90 \mathrm{mg} /$ daily but experienced three episodes of elevated blood pressure. HLA B27 typing was positive. Radiographs of the spine showed the presence of bone bridge sindesmophytes and sclerosis of the vertebral somatic limits.

Magnetic resonance showed a cancellous osteitis of L2, L3, and L4 involving the somatic edges of the vertebral body. Contrast enhancement was seen of the central part of the L2-L3, L3-L4, and L4-L5 discs, of the postero-lateral left paraspinal area, and of the left paravertebral venous plexus. Sacroiliitis with bone edema was also present. Blood coltures were negative for yersinia, brucella, streptococcus and staphylococcus; Salmonella paratyphy B serodiagnosis was positive, probably indicating natural infection or prior vaccination.

Mantoux test and Quantiferon were negative. Routine blood examination showed erythrocyte sedimentation rate $49 \mathrm{~mm} / \mathrm{h}$ (n.v. $<20 \mathrm{~mm} / \mathrm{h}$ ), C-reactive protein 1.31 mg/dL (n.v. $<0.5 \mathrm{mg} / \mathrm{dL}$ ), interleukin-6 4.1 $\mathrm{pg} / \mathrm{mL}$ (n.v. $<3.2 \mathrm{pg} / \mathrm{mL}$ ), and tumor necrosis factor $\alpha 17.3 \mathrm{pg} / \mathrm{mL}$ (n.v. $<15.6 \mathrm{pg}$ / $\mathrm{mL}$ ). ASDAS activity score was 2.4 .

The 2-deoxy-2- [18F]fluoro-D-glucosepositron emission tomography/computed tomography (18F-FDG-PET/CT) showed an increased tracer uptake of the spinal spaces of L2-L3 and L3-L4 compatible with spondylodiscitis. An uneven uptake was observed also at the left posterolaterla border of L4-L5 (Figure 1).

The patient was diagnosed with spondylodiscitis in HLA B27-positive spondyloarthritis (ASAS Criteria) and started therapy with etanercept, $50 \mathrm{mg} /$ week.

After six months of treatment, repeated 18F-FDG-PET/CT showed no uptake of the discs and vertebral bodies (Figure 2).

Aseptic spondylodiscitis is a complicating feature of ankylosing spondylitis (AS) (1). The clinical presentation may vary from asymptomatic to localized back pain. Serious spinal cord damage has exception-
Corresponding author Maurizio Benucci Rheumatology Unit, Azienda Sanitaria USL-Centro Hospital S. Giovanni di Dio Via Torregalli, 3 - 50143 Florence, Italy E-mail:

maubenucci@tiscali.it

maurizio.benucci@usicentro.toscana.it 


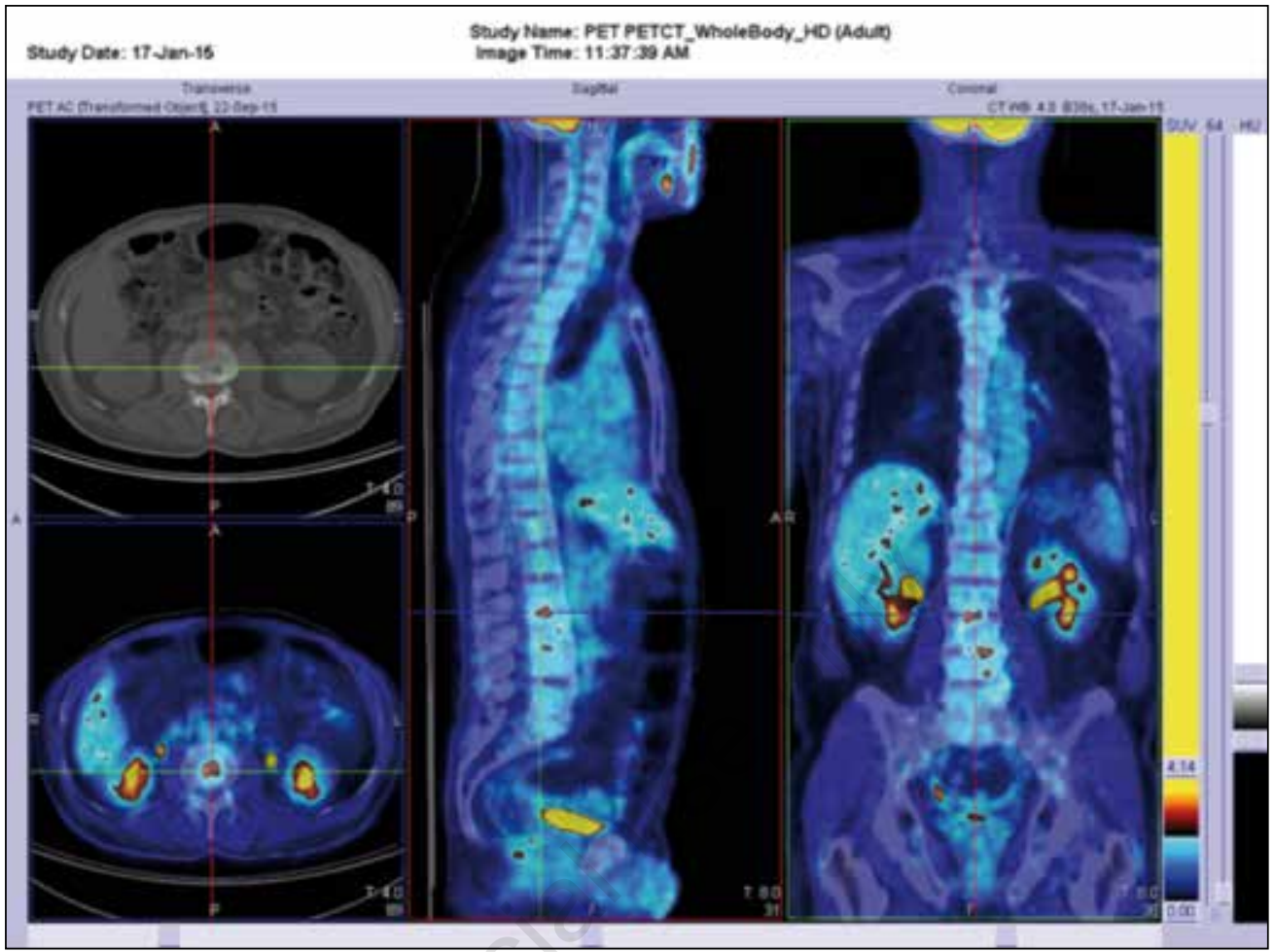

Figure 1 - 18F-FDG-PET/CT showed an increased metabolism at the level of the spinal space of L2-L3 L3-L4.

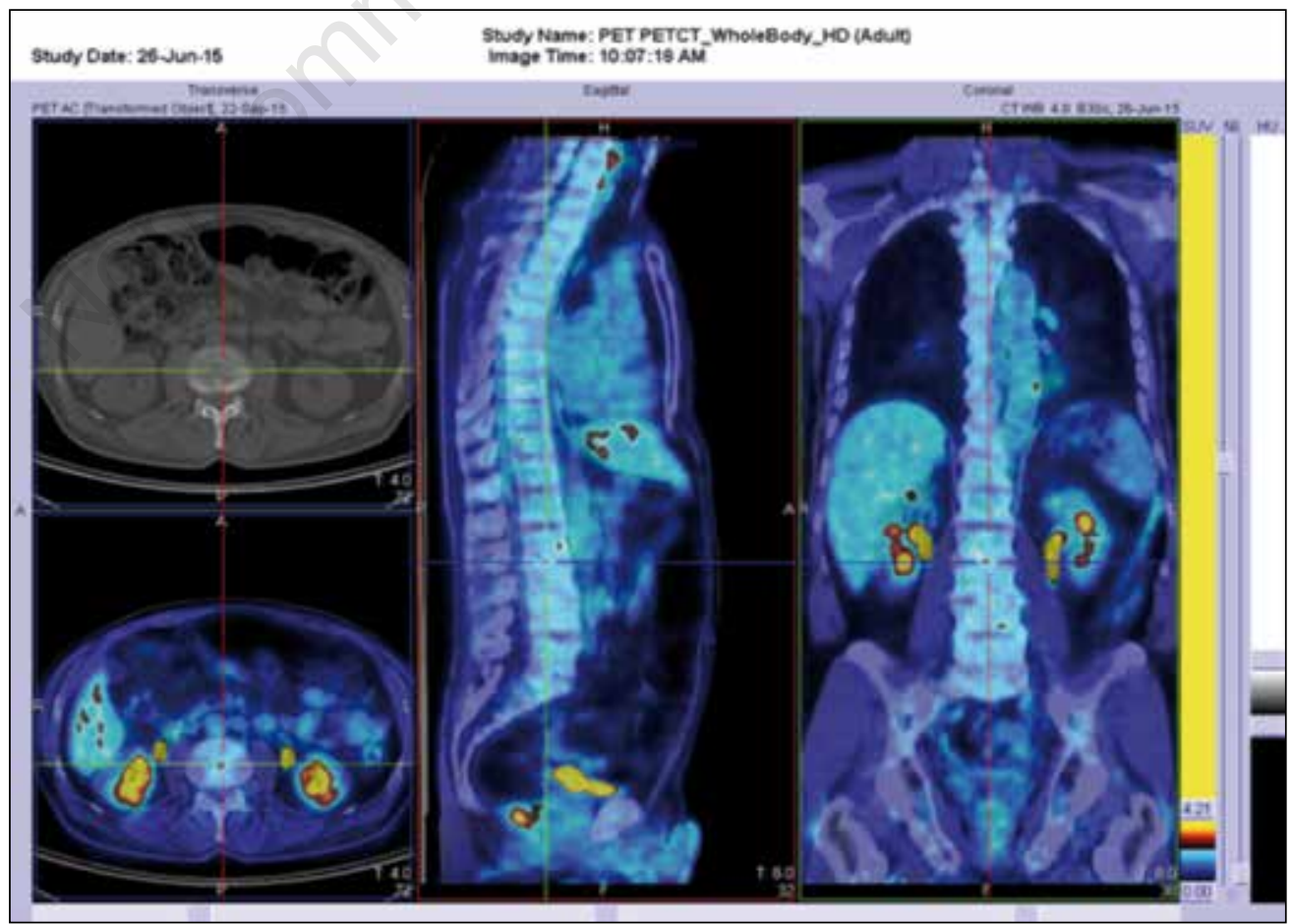

Figure 2 - 18F-FDG-PET/CT after six months of treatment repeat testing showed no uptake of the discs and vertebral bodies. 
ally been described in association with spondylodiscitis in AS (2). The frequency of aseptic discitis in patients with AS is probably overestimated as a result of inclusion of degenerative lesions but also because of exclusion bias. The prevalence of destructive lesions varies between $1 \%$ and $28 \%(2,3)$.

In spite of the findings in our patient, the positive predictive value of $18 \mathrm{~F}-\mathrm{NaF}$ PET for diagnosing spondyloarthritis or predicting a response to TNF antagonist therapy seems to be inconsistent (4).

\section{REFERENCES}

1. Cawley MID, Chamlers TM, Kellgren JH, Ball J. Destructive lesions of vertebral bodies in ankylosing spondylitis. Ann Rheum Dis. 1972; 31: 345-58.

2. Toussirot E, Chataigner H, Pépin L, et al. Spinal cord compression complicating aseptic spondylodiscitis in ankylosing spondylitis. Clin Exp Rheumatol. 2009; 27: 654-7.

3. Langlois S, Cedoz JP, Lohse A, et al. Aseptic discitis in patients with ankylosing spondylitis: a retrospective study of 14 cases. Joint Bone Spine. 2005; 72: 248-53.

4. Darrieutort-Laffite C, Ansquer C, Maugars Y, et al. Sodium (18) F-sodium fluoride PET failed to predict responses to TNF $\alpha$ antagonist therapy in 31 patients with possible spondyloarthritis not meeting ASAS criteria. Joint Bone Spine. 2015; 82: 411-6. 